\title{
The Prediction of Wind Power Generation: A Case Study in South Korea
}

\author{
Jun-Sung Kim, Jin-Ho Shin, Young-Bae Park, and Hee-Jeong Park
}

\begin{abstract}
It is difficult to predict the power generation amount of wind turbines because it is depending on weather condition. However it is important to predict wind power generation amount accurately, because it is possible to maximize the utilization of wind turbines, and also establish more effective operation plan of grid. The purpose of this study is to increase the accuracy of prediction of the power generation amount. To increase accuracy, we built the 3 dimensional weather research and forecasting model that is the most applicable to our developing district environment. In case of short-term prediction within 6 hours, to overcome the weakness that cannot reflect the regional characteristics for particular areas enough, we predicted weather information considering statistical characteristics such as weather pattern change information of wind plants. Using the result of weather prediction as a basic data, we computed the power generation amount by plants and wind generators. In the proposed approaches, inaccuracies are analyzed based on the combination of physical model and statistical model. The result of the analysis showed $15.7 \%$ (within 24 hours), and $17.5 \%$ (within 48 hours) error rate.
\end{abstract}

Index Term-Short and midterm prediction of wind power, wind power generation forecasting system, distributed generation.

\section{INTRODUCTION}

The recent development of smart grid and micro grid has increased the utilization of the distributed resources. However, it is difficult to predict the power generation amount of renewable energy resources such as wind turbines and photovoltaics because they are extremely depending on weather condition. If we can predict the power generation amount from renewable resources in advance, we can maximize utilization of renewable resources and also establish operation plan of grid. Furthermore, it is expected to see the effect of the cost reduction following with economic dispatch because operating reserve can be managed efficiently [1].

As the goal of this study, we set production of prediction information of wind power that is as accurate as commercialization is possible. To predict more accurate wind power, first, we built the model that is the most applicable to our developing district environment through a 3 dimensional

Manuscript received November 15, 2015; revised March 3, 2016. This work was supported by the Power Generation \& Electricity Delivery Core Technology Program of the Korea Institute of Energy Technology Evaluation and Planning (KETEP) granted financial resource from the Ministry of Trade, Industry \& Energy, Republic of Korea (No. 20141010501870).

Jun-Sung Kim, Jin-Ho Shin, Young-Bae Park, and Hee-Jeong Park are with the Korea Electric Power Research Institute, Daejeon, Munji-Road 105, Korea (e-mail: \{junskim, jinho, parkyb, parkhj3\} @ kepco.co.kr). weather research and forecasting model that is utilized the most in the world. Also, in case of short-term prediction within 6 hours, to overcome the weakness that cannot reflect the regional characteristics for particular areas enough, which is the weakness of a general physical model, we predicted weather information considering statistical characteristics such as weather pattern change information of wind plants. Using the result of weather prediction as a basic data, we computed the power generation amount by plants and wind generators. The above-mentioned process is described in Fig 1. As a result of the study, we completed the development of the prediction technology of wind power generation amount at the level of advanced countries and provided the opportunity for stable system connection of dispersal outlets.

As the components of this thesis, in Section II, real time weather prediction technology will be explained and in Section III, the prediction process for the wind power generation amount of particular areas based on the weather prediction technology described in Section II. In Section IV, the prediction result of wind power generation amounts will be explained.

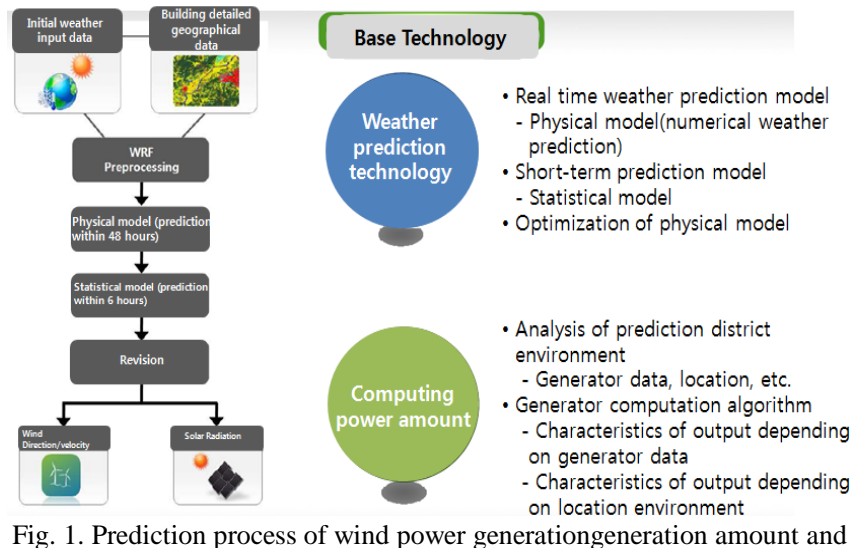
base technology.

\section{DeVelopment of REAl Time WeAther PREDICTION MODEL}

\section{A. Process of Initial Meteorological Model and Geographical Map}

Because wind power is largely influenced by geography, building geographical data of the target area within physical model to predict wind accurately. Especially, to predict the weather of a particular area, detailed geographical data has to be built and the geographical condition of the area to predict has to be reflected accurately. Here, geographical data means topography altitude and ground surface covering, etc. Topography altitude is the factor that decides air current and it 
occurs the change of wind velocity by influencing geographical frictional force following the ground surface covering. To forecast the weather of a particular region where wind plants are installed and operated, first, the resolution of weather model has to be high and geographical data that are applicable to resolution has to be built. Especially, since the wind that is the energy source of wind power gets influenced largely by the geography, detailed geographical data has to be built in order to get accurate wind prediction [2].

In this study, we set 3 prediction areas in Mt. Taegi, Gangwon wind plant, Gunsan, and built the weather model with resolution under $1 \mathrm{~km}$ for the relevant areas. In this process, we used the environmental geography information that is $100 \mathrm{~m}$ interval resolution provided by the Ministry of Environment and set Gangwondo $(55 \mathrm{~km} \times 55 \mathrm{~km})$ and Jeollado $(55 \mathrm{~km} \times 55 \mathrm{~km})$ as final prediction areas. And we utilized the latest environmental geography information of the Ministry of Environment for detailed geography data and we also used Digital Elevation Model of United states Geological Survey for partial data that are not provided by the Ministry of Environment. For the method that built the weather model of $1 \mathrm{~km}$ resolution, we applied the Nesting Method of the time setting up the prediction area on the physical model WRF [3]. This is the method that produces the forecast of small prediction areas (Domain 2, 3, 4, 5, 6) by the levels based on having this result as initial field after performing the model that targets East Asian areas (Domain 1) including South Korea. Through the process above, we built the detailed environmental geography information that is necessary to improve the accuracy of the wind prediction and also built the weather model that has the resolution less than $1 \mathrm{~km}$ and is centered in 2 prediction regions (see Table I).

TABLE I: PREDICTION AREA DOMAIN INFORMATION [4]

\begin{tabular}{|l|c|c|c|c|c|c|}
\hline \multicolumn{1}{|c|}{ Division } & Domain 1 & $\begin{array}{c}\text { Domain } \\
2\end{array}$ & $\begin{array}{c}\text { Domain } \\
3\end{array}$ & $\begin{array}{c}\text { Domain } \\
4\end{array}$ & $\begin{array}{c}\text { Domain } \\
5\end{array}$ & $\begin{array}{c}\text { Domain } \\
6\end{array}$ \\
\hline $\begin{array}{l}\text { East and West } \\
\text { Direction Grid }\end{array}$ & 91 & 61 & 70 & 64 & 55 & 55 \\
\hline $\begin{array}{l}\text { South and } \\
\text { North Direction } \\
\text { Grid }\end{array}$ & 91 & 73 & 70 & 64 & 55 & 55 \\
\hline $\begin{array}{l}\text { Resolution } \\
\text { (Grid interval) }\end{array}$ & $27 \mathrm{~km}$ & $9 \mathrm{~km}$ & $3 \mathrm{~km}$ & $3 \mathrm{~km}$ & $1 \mathrm{~km}$ & $1 \mathrm{~km}$ \\
\hline
\end{tabular}

\section{B. Optimization of Physical Models}

To predict accurate weather, the accuracy of the forecast data of physical model that is used in prediction has to be high. However, because general physical model is set to produce the forecast of wide area and its accuracy of a particular region is relatively low, the various physical equations and physical process options that are included in the physical model have to be optimized so that it can be the most relevant for the regional characteristics [5]. The optimizing operation of the forecasting model has proceeded after performing the physical model targeting past period of the prediction area, comparing/analyzing observation data and forecasting data, and testing various physical options depending on weather patterns such as day and night, seasons, etc. Because the prediction regions of this study are 2 locations in Gangwon (Mt. Taegi, Gangwon Wind Plant) and 1 location in Jeollado (Gunsan), we implemented analysis using the experimental value of the weather observation points installed in 3 locations.

The optimizing process of the physical model consists of 3 stages as below, and the chart that puts this process more in detail is in Table II and Fig. 2 below. It represents the Phase 1 as the stage from 'selection of the environment with basic physical option' to 'WRF performance for each test environment', Phase 2 as the stage of 'verification of errors', and Phase 3 as the stage of 'selection of the environment by each basic physical option' and 'optimization of option setting'.

TABLE II: OPTIMIZATION PROCESS OF PHYSICAL MODEL

\begin{tabular}{|c|l|}
\hline Stage & Explanation \\
\hline Phase 1 & $\begin{array}{l}\text { This is the stage of performing WRF model. After } \\
\text { selecting the weather patterns that represent the region } \\
\text { through the climate analysis of the targeted area by } \\
\text { seasons, months, the frequency, and time, the physical } \\
\text { model during the period that relevant pattern appears is } \\
\text { performed. }\end{array}$ \\
\hline Phase 2 & $\begin{array}{l}\text { This is the stage of comparing the performance result of } \\
\text { the physical model and experimental value. the } \\
\text { comparison and analysis between 1 km interval weather } \\
\text { prediction value computed through performing the } \\
\text { physical model and main experimental data within } \\
\text { targeted prediction area are performed. }\end{array}$ \\
\hline Phase 3 & $\begin{array}{l}\text { This stage repeats the process above changing the } \\
\text { physical process option within the physical model, and } \\
\text { sets the physical option environment that is the most } \\
\text { relevant to the characteristics of the weather of the targeted } \\
\text { prediction area through comparison between the model } \\
\text { value and experimental value }\end{array}$ \\
\hline
\end{tabular}

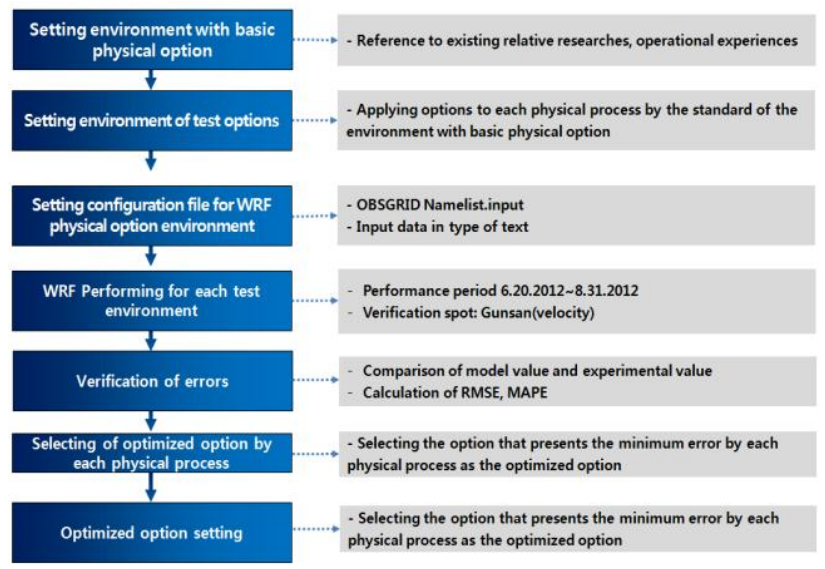

Fig. 2. Outline of optimization of physical model.

TABLE III: The Result of THE SELECTION OF PHySiCAL Model Options

\begin{tabular}{|c|c|c|c|c|c|}
\hline Physical Process & Option & MAPE(\%) & $\begin{array}{l}\text { Physical } \\
\text { Process }\end{array}$ & Option & $\operatorname{MAPE}(\%)$ \\
\hline \multirow{8}{*}{ Microphysics } & Kessler scheme & 32 & \multirow{3}{*}{$\begin{array}{l}\text { Surface } \\
\text { Layer }\end{array}$} & MM5 similarity & 23 \\
\hline & Lin et al. scheme & 30 & & Eta similarity & 37 \\
\hline & WRF single-Moment 3,5,6-class scheme & 28 & & Pleim-Xiu surface layer & 29 \\
\hline & Eta microphysics & 39 & \multirow{4}{*}{$\begin{array}{l}\text { Land } \\
\text { surface }\end{array}$} & 5-layer thermal diffusion & 26 \\
\hline & Goddard microphysics scheme. & 38 & & Noah Land Surface Model & 28 \\
\hline & New Thompson et al. scheme & 37 & & RUC Land Surface Model & 39 \\
\hline & Morrison double-moment scheme & 42 & & Pleim-Xiu Land Surface Model & 34 \\
\hline & WRF Double-Moment5,6-class scheme & 31 & \multirow{3}{*}{$\begin{array}{c}\text { Planetary } \\
\text { Boundary } \\
\text { layer }\end{array}$} & Yonsei University scheme & 27 \\
\hline \multirow{3}{*}{$\begin{array}{l}\text { Lonqwave } \\
\text { Radiation }\end{array}$} & RRTM scheme & 26 & & Mellor-Yamada-Janjic scheme & 38 \\
\hline & GFDL scheme & 32 & & MRF scheme & 32 \\
\hline & CAM scheme & 39 & \multirow{5}{*}{$\begin{array}{l}\text { Cumulus } \\
\text { Parameter } \\
\text {-izztion }\end{array}$} & Grell-Devenyi ensemble scheme & 41 \\
\hline \multirow{4}{*}{$\begin{array}{l}\text { Shortwave } \\
\text { Radiation }\end{array}$} & Goddard shortwave & 41 & & Betts-Miller-Janjic scheme & 33 \\
\hline & Duchia scheme & 31 & & Kain-Fritsch scheme & 32 \\
\hline & GFDL shortwave & 35 & & Grell 3d ensemble cumulus schene & 36 \\
\hline & CAM scheme & 37 & & Old Kain-Fritsch scheme & 37 \\
\hline
\end{tabular}


The optimization of weather physical model performed each process of the Fig. 2 above consecutively and repeatedly and through this, the most relevant physical option has selected to weather prediction of Daekwanryeong and Gunsan area. At the time of selecting physical option, I set the option that showed the lowest result in MAPE (Mean Absolute Percentage Error) by prediction time after comparing model value and experimental value and the result of the selection is like the Table III.

\section{Prediction of Short/Mid-term Wind Velocity}

To predict power generation amount that is produced from wind plants, short-term prediction of power generation amount within 6 hours and mid-term prediction of power generation amount from 6 hours to 48 hours can be performed. Generally, the physical model is the prediction model that considers the changes of the regional meteorological model accordingly with medium-scale weather changes and fits in mid-term prediction after 6 hours [6]. So for a short-term prediction within 6 hours, the prediction method can consider that the characteristics of statistical model have to be applied. Therefore, the combination model that uses the physical model and the statistical model at the same time has been developed for the short-term model within 6 hours in this study. For the prediction after 6 hours, the statistical model was not applied and the wind velocity was predicted using the physical model.

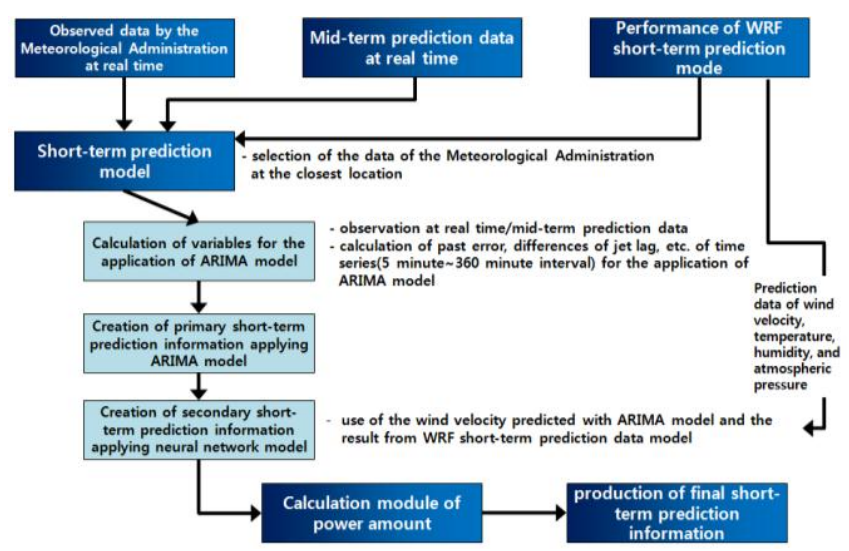

Fig. 3. The structure chart of short-term prediction model process.

The representative statistical methods used for the short-term prediction of wind velocity are multiple regression, neural network, and ARIMA (auto-regressive moving average), etc. and there are cases that more than 2 methods of these methods are combined and used. In this study for a short-term prediction of wind velocity, ARIMA and neural network are combined. For the input data used in the process of short-term prediction, real time observation data and real time mid-term prediction data provided by the Meteorological Administration are used. Based on these two data above, using ARIMA model established, we produced primary short-term prediction information. And by applying the result of the primary short-term prediction using this ARIMA model to the neutral network again, we produced the final/secondary short-term prediction information. Besides the physical model for production of real time mid-term prediction data in this process, WRF physical model is performed separately for a short-term prediction, 5 minute interval prediction information of the weather produced here is used as input data of the neural model. The short-term prediction model process for wind velocity, which is explained above is in the Fig. 3.

For the short-term prediction model of wind velocity, short-term prediction is performed based on ARIMA and the regressive integrated model with independent variables. From the Fig. 3 above, for setting independent variables that are applied to the second stage, we selected total 5 types of velocity that were the wind velocity 5 minutes ago, 10 minutes ago, and 15 minutes ago as of now, fixed time wind velocity before prediction hour and fixed time wind velocity after prediction hour. Based on experimental wind velocity of 5 minute interval and 5 types of independent variables, we created ARMA model by each precedent time ( 5 minutes 360 minutes, 5 minute interval) of the prediction. The Table below represents part (10 minutes 12 minutes) of the differences or ARIMA model created for the short-term prediction performance.

Through the process of the Fig. 3, based on the fact that the difference between the wind velocity predicted by ARIMA model primarily created and the experimental wind velocity become different depending on the weather pattern such as wind direction, wind velocity, temperature, and humidity, etc, of the predicted area, we predicted the error value of ARIMA model through secondarily neural network model and revised the predicted value of wind velocity by applying this to the neural network model. In other words, as the Fig. 4, we predicted the general pattern of wind velocity through optimization of physical model, and applied the method that predicted the nonlinear part by the weather pattern after predicting the variability according to the time through ARIMA model.

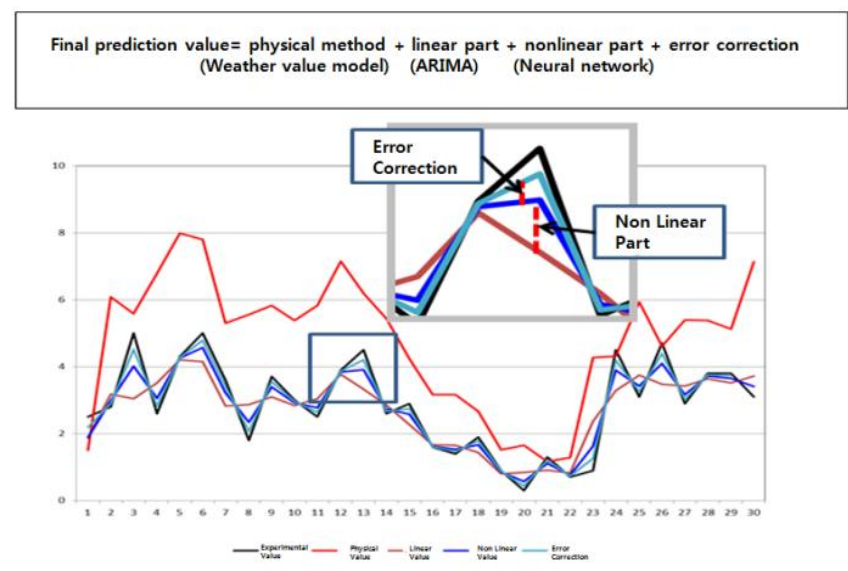

Fig. 4. The structure chart of the process of short-term prediction model.

In order to draw the neural network model, we set the process that neural network model is applied with according to Fig. 5 process. We used 5 minute interval weather data of Daekwanryeong (Mt.Taegi and Gangwon wind plant) and Jeolla (Gunsan) that are prediction area of wind power generation amount and there are total 5 types of weather data used such as wind velocity, wind direction, temperature, humidity and atmospheric pressure. Weather patterns are classified to total 48 types. Wind direction is divided to total 8 directions from 0 degree to 360 degree, and wind velocity is divided to total 6 stages which are 5 stages from $0.5 \mathrm{~m} / \mathrm{s}$ to 15 $\mathrm{m} / \mathrm{s}$ and over $15 \mathrm{~m} / \mathrm{s}$. Applying this classification, we 
classified the error of the prediction value of ARIMA model and applied the calculated variable to neural network as Fig. 6.

1) Dependent variable: the error of the prediction value of the wind velocity of ARIMA model.

2) Weather factor: the prediction value of the wind velocity of ARIMA model, wind direction, temperature, humidity, atmospheric pressure.

And we calculated weighted value by the weather pattern of each targeted prediction area (Gangwondo, Jeollado) and calculated weighted value of neural network model according to the pattern after recognizing the patterns of short-term physical model prediction value (wind velocity, wind direction, temperature, humidity, atmospheric pressure) and drawing the neural network model for error prediction of ARIMA model prediction value. And applying the neural network model to ARIMA model, we calculated the short-term prediction value that combines ARIMA model and neural network model [7].

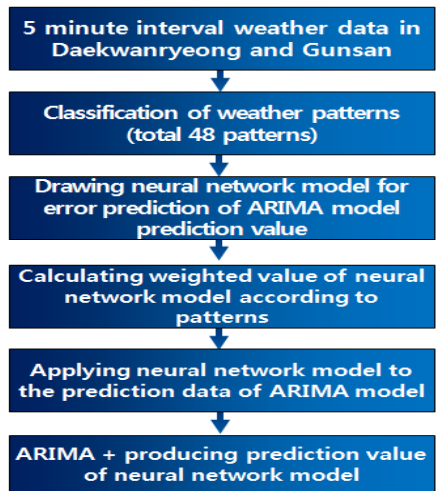

Fig. 5. The process that neural network model is applied with.

As a result of applying the process above and drawing the neural network model based on the weather data in Gangwondo and Jeollado, the model that composed 4 hidden layers about all weather patterns was drawn. The composed model calculates constant term (bias) on input layer and hidden layer depending on each input variable and weighted value on the 4 layers. Constant term (bias) of the hidden layer and output layer and weighted value of 4 hidden layers are calculated and applied to the neural network model. The detailed model that applies to the neural network model shows at Fig. 6 and Fig. 7.

1) Standardization using the average value and variance of input variables to apply the neural network model

$$
\text { Standardized value }=\frac{\text { Variable }- \text { Average }}{\text { Variance }}
$$

2) Applying weighted value by weather pattern to each standardized input variable as follows.

$$
L I=\omega 1 X 1+\ldots \ldots+\omega p X p+\operatorname{Bias}
$$

where $\omega$ : weighted value between input layer of each variable and hidden layer, $X$ : standardized input variable.

3) Calculating activation function for each hidden layers, sigmoid function that is used the most generally is applied to the neural network model in this study.

$$
S(\text { Sigmoid Function })=\frac{1}{1+\exp (-L I)}
$$

4) Weighted value is applied to sigmoid function value of each hidden layer

$$
L O=\omega 1 S 1+\omega 2 S 2+\omega 3 S 3+\omega 4 S 4+\mathrm{Bias}
$$

where $\omega$ : weighted value between each hidden layer and output layer, $S$ : sigmoid function of each hidden layer.

5) Calculating activation function value of output value

$$
S(\text { Sigmoid function of output layer })=\frac{1}{1+\exp (-L O)}
$$

6) Revising wind velocity by adding output layer value calculated through the neural network model with ARIMA model prediction value.

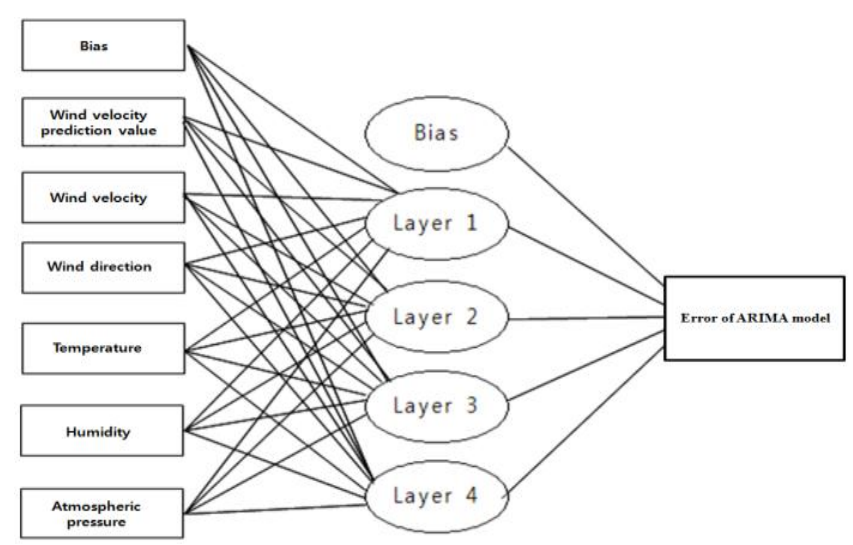

Fig. 6. Neural network model structure.

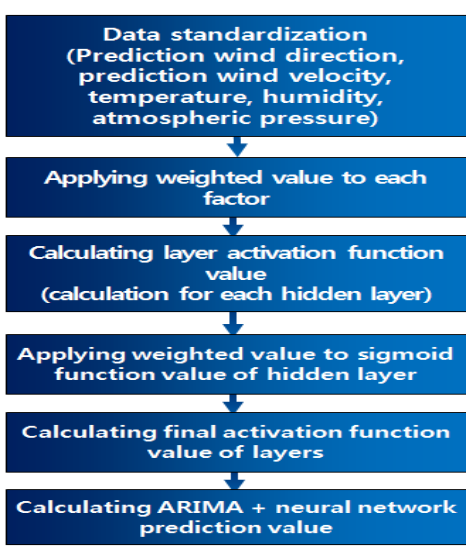

Fig. 7. Detailed algorithm of neural network model.

\section{Prediction of Short/Mid-term Velocity}

The model of short-term wind velocity in this study consisted of ARIMA model as the stage 1 and neural network model as the stage 2 . The error rate of each stage for the result of the performance of prediction of short-term wind velocity is shown at Fig. 8. To sum up the results, first for the whole wind velocity, MAPE of ARIMA and neural network integrated model reduced $1.9 \%$ in average and $3.0 \%$ maximum compared to single ARIMA model. Also, RMSE of 
ARIMA and neural network integrated model reduced $0.03 \mathrm{~m} / \mathrm{s}$ in average and $0.1 \mathrm{~m} / \mathrm{s}$ maximum compared to single ARIMA model. For cut-in velocity, MAPE of ARIMA and neural network integrated model reduced $0.9 \%$ in average and 1.5\% maximum compared to single ARIMA model. Also, RMSE of ARIMA and neural network integrated model reduced $0.07 \mathrm{~m} / \mathrm{s}$ in average and $0.1 \mathrm{~m} / \mathrm{s}$ maximum compared to single ARIMA model. As a result of the analysis of correlation between prediction value of short-term wind velocity and experimental value, coefficient of determination appeared more than 0.65 at precedent time slot of all prediction and this means coefficient is about 0.8 and it is judged not to be hard on wind velocity prediction (See Fig. 9).
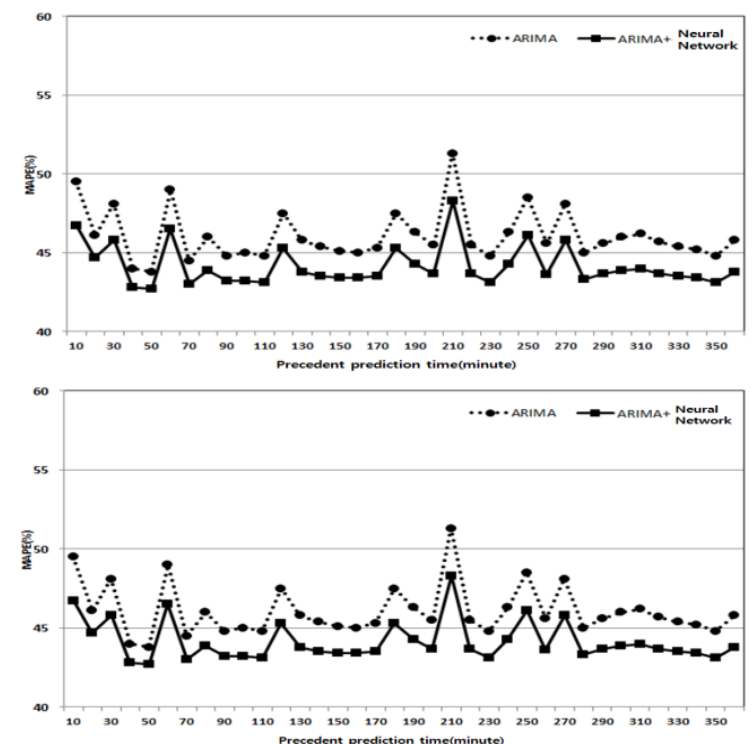

Fig. 8. Result of the short-term prediction of wind velocity.

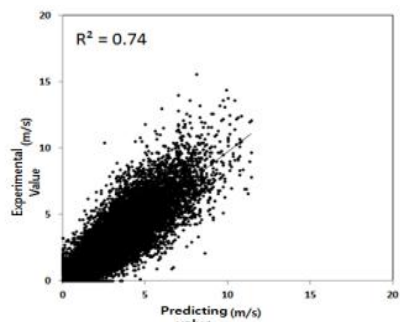

10 Minutes

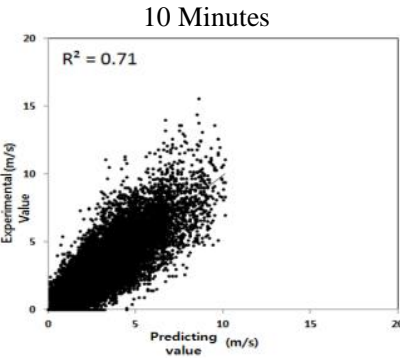

60 Minutes

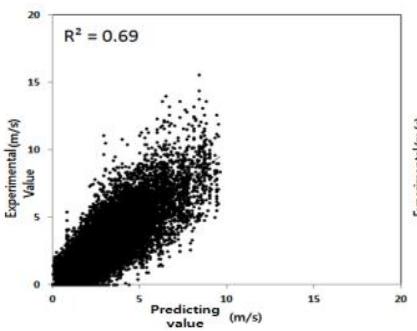

240 Minutes

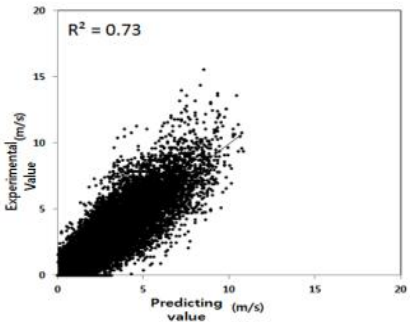

30 Minutes

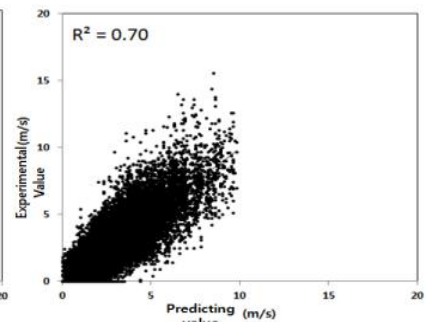

120 Minutes

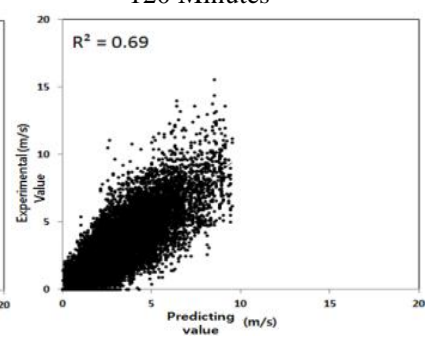

360 Minutes

Fig. 9. Correlation between prediction value of short-term wind velocity and experimental value.
As the result of the prediction of mid-term wind velocity and the result of the analysis of the accuracy of weather prediction using the data of wind direction and wind velocity in Gunsan, the average of prediction value of whole $\mathrm{mid} /$ long-term was predicted $2.3 \mathrm{~m} / \mathrm{s}$ which was about $0.3 \mathrm{~m} / \mathrm{s}$ lower than the experimental value $2.6 \mathrm{~m} / \mathrm{s}$ and the error rate was analyzed to $38.4 \%$. The error rate by precedent prediction time was $42.3 \%$ for 6 hours, $42.7 \%$ for 24 hours, and $45.9 \%$ for 48 hours (See Tables IV, V). The pattern of time series during the analysis period showed the similar pattern with experimental wind velocity, so it was judged to be appropriate to use the wind velocity predicted through the weather physical model as the basic date of power generation amount prediction.

TABLE IV: THE ACCURACY OF THE PREDICTION OF THE WIND VELOCITY IN GUNSAN

\begin{tabular}{|c|c|c|}
\hline & Experimental value & Predicting value \\
\hline $\begin{array}{c}\text { Wind velocity in } \\
\text { average }(\mathrm{m} / \mathrm{s})\end{array}$ & 2.6 & 2.3 \\
\hline $\mathrm{RMSE}(\mathrm{m} / \mathrm{s})$ & - & 1.4 \\
\hline NMAE $(\%)$ & - & 38.4 \\
\hline
\end{tabular}

TABLE V: The ACCuRACy By the PRECEDENT TIME IN GUNSAN

\begin{tabular}{|c|c|c|c|}
\hline & 6 hours & 24 hours & 48 hours \\
\hline $\begin{array}{c}\text { Wind velocity } \\
\text { in average }(\mathrm{m} / \mathrm{s})\end{array}$ & 2.7 & 2.8 & 2.5 \\
\hline RMSE $(\mathrm{m} / \mathrm{s})$ & 1.4 & 1.7 & 1.3 \\
\hline NMAE $(\%)$ & 41.4 & 46.8 & 42.6 \\
\hline
\end{tabular}

III. DEVELOPMENT OF THE PREDICTION SYSTEM FOR WIND POWER GENERATION

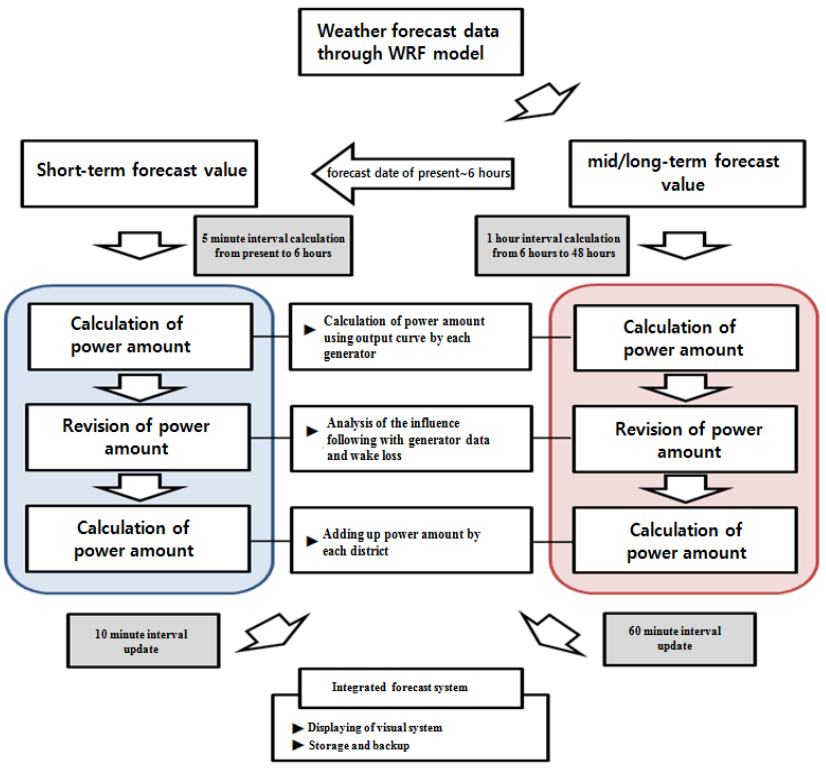

Fig. 10. The calculation algorithm of wind power generation amount.

As Fig. 10 in this study shows, the final prediction value of wind power generation amount is calculated using the prediction value of the real time weather data in targeted area and the wind power generation amount is calculated by inputting the modification factor by wind power generator and processing the calculation of wake loss ratio according to 
the geographical location of the generators, considering generator data and power generation amount factor. Generally, when calculating wind power generation amount, there is sometimes a case where there is no power generation amount accordingly with the curve of the power generation amount by generators. This is because of the condition of the maintenance and management of the generators and the surrounding environment, etc., so we calculated the final power generation amount based on the evaluation of the data of the performance and uncertainty of the generators within wind power plant district, when predicting the power generation amount through the wind prediction value in this study.

Because the height of turbine can be different depending on the model of wind power generators, the revision of the wind velocity by generators is necessary. We revised the prediction wind velocity of the physical model to the wind velocity of the turbine height by each generator using DEACON equation. On the process of revision, we analyzed the arrangement of the generator accordingly with the wind direction, using the coordinate of the longitude and the latitude of wind power plants, and revised the wind velocity reduced due to the wake loss. Also, using the input data of the power curve by each generator and applying spline interpolation, we calculated the power generation amount. DAECON equation applied to revise to the wind velocity of turbine height by generators is as the expression below. According to the equation below, $\rho$ is the measure that represents atmospheric stability and it is also called wind shear and decided by geographical changes and surface roughness. In other words, when the wind velocity that has the same spot of measurement and more than 2 locations of different heights is measured, it is possible to get the wind shear like the equation (2) by stimulating the equation (1) with extrapolation.

$$
\frac{v}{v_{1}}=\left(\frac{z}{z_{1}}\right)^{\partial}
$$

$v$ : Wind velocity on the $z$ altitude $(\mathrm{m} / \mathrm{s})$;

$z$ : Altitude calculating wind velocity $(\mathrm{m})$;

$\partial$ : Scale factor of wind velocity.

$$
\rho=\frac{\ln \left(\frac{v}{v_{1}}\right)}{\ln \left(\frac{z}{z_{1}}\right)}
$$

$v_{1}$ : Wind velocity on the $z_{1}$ altitude $(\mathrm{m} / \mathrm{s})$;

$z_{1}$ : Altitude calculating wind velocity $(\mathrm{m})$.

Secondly, according to the process suggested in Fig. 10, we calculated the wind velocity that reduced due to the wake loss of the wind power plant. The reason why wind velocity reduces because of the generator's wake is because the wind velocity measured in the right rear side of the router reduces rapidly compared to the wind velocity approaching to the surface of the router after extracting energy in wind power turbine, and the turbulence of the air near hub height increases, and the currency that falls out rearwards occurs wind wake because of the rotation of the routers. Generally it is known that the wind velocity of the air current that passes wind power turbine router reduces up to about $40 \%$ maximum and the turbulence intensity increases largely from wind wake. When two wind power turbine is arranged consecutively from the construction of the district, the output of rear turbine generally causes the reduction up to about $10 \sim 20 \%$ for rear wind power turbine and up to about $60 \%$ maximum at the worst because of the influence by the wind wake by the wind power turbine installed in the front. To consider the effect of this wind wake, we revised the wind velocity of the generators in the range of the effect of wind wake using predicted wind direction. The detailed process of the revision includes researching generators within the range of the wind wake behind depending on the wind direction first, calculating the included areas and calculating thrust coefficient $\left(C_{t}\right)$ which is the power that the wind that works to the router pushes wind power turbine.

$$
\text { Thrust coefficient definition: } C_{t}=\frac{2 F_{t}}{\rho \pi R^{2} U^{2}}
$$

And we calculated the reduced wind velocity of the rear generators, substituting each variable to the equation like Fig 11. Here, the power that the wind that works to the router pushes the wind power turbine backwards is called thrust force and the dimensionless thrust coefficient $C_{t}$ is as follows. With the wind velocity of the wind wake loss calculated like this, the reduced wind velocity was calculated using $C_{t}$ value depending on the wind velocity and estimating the area that include the rear router in the influence range of the wind wake of front turbine by using of equation (4), (5).

$$
V=U\left[1-\left(1-\sqrt{1-C_{t}}\right)\left(\frac{D}{D+2 k X}\right)^{2}\right]
$$

$$
\delta V_{01}=U_{0}\left(1-\sqrt{1-C_{t}}\right)\left(\frac{D_{0}}{D_{0}+2 k X_{01}}\right)^{2} \cdot \frac{A_{\text {overiop }}}{A_{1}}
$$

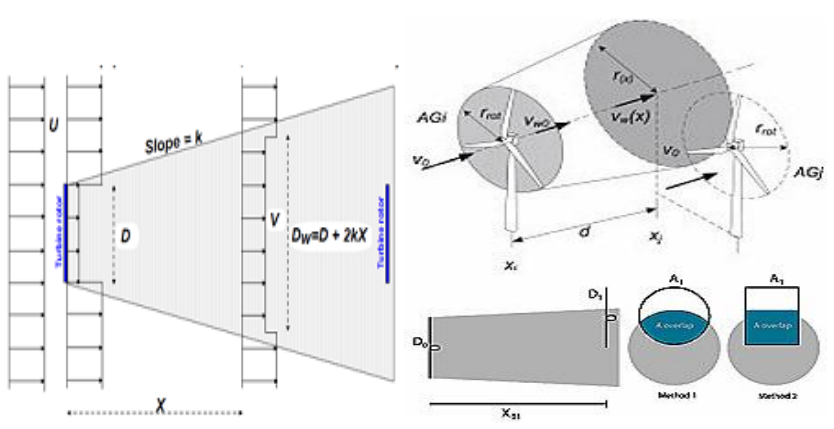

Fig. 11. Calculation of wind wake loss wind velocity [8].

Finally, to calculate the power generation amount of the wind velocity, we calculated the power generation amount of the predicted wind velocity through Cubic Spline interpolation [9]. Cubic Spline interpolation is a connecting polynomial function that applies the subset of data points to 
polynomial expression of a lower order. Generally the function changes gradually but there are cases that it changes drastically in some particular area and because it provides excellent approximate values, it is used a lot for the movement of the function that changes drastically and locally. Fig. 12 below explains the algorithm of power curve calculation that applies Cubic Spline interpolation according to the power curve information that the generator-producing company provides.
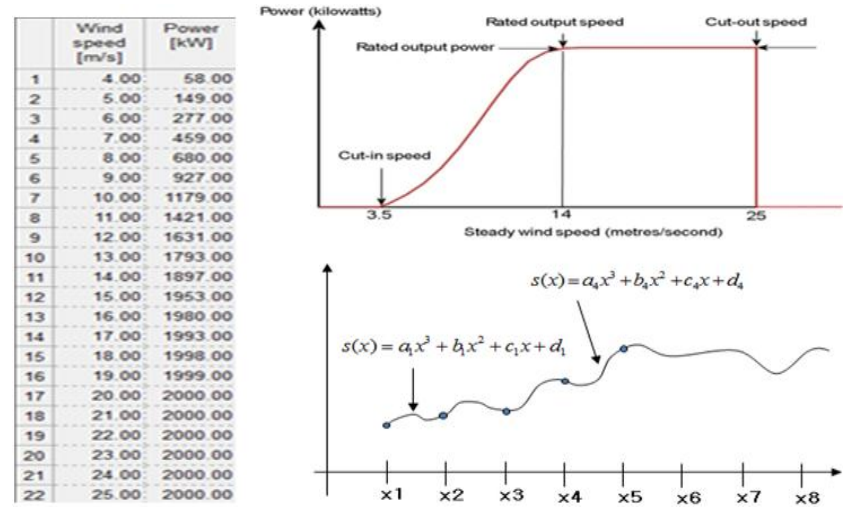

Fig. 12. Algorithm of power curve calculation [10].

\section{CONCLUSIONS}

To evaluate the accuracy of the prediction of wind power generation amount in this system, we used the predicting value and measuring value of the power generation amount, targeting major wind power plant district within the prediction area. The target of the analysis is the generators in Gangwon Wind Power Plant in Daekwanryeong and the ones in Mt. Taegi Wind Power Plant and the target of the Jeonbuk area is the generator within the wind power plant district. To evaluate the accuracy of the prediction, we calculated the error rate comparing the measuring data by the schedule of each district, and used the measuring value that was measured in June 2012 February 2013 for the analysis data. The error rate was calculated for whole district by adding all the capacity of the three districts and compared the calculation with the capacity by each district. As you can see Table VI, for the whole wind power generator targeted for prediction, it showed $12.5 \%$ for 1 hour of precedent prediction, $13.3 \%$ for 6 hours, $14.0 \%$ for 12 hours, and $15.7 \%$ for 24 hours, so it showed less than $20 \%$ of error rate for 24 hours which is the goal of the prediction error rate of this project. For each district, the error rate of Jeonbuk Wind Power Plant showed about $10 \sim 12 \%$ error rate for all precedent prediction hours, which was the highest accuracy, while the error rate of Mt. Taegi Wind Power Plant and Gangwon Wind Power Plant showed about 15 22\% error rate, which was relatively low accuracy. For the evaluation result of system performance, the error rate of the whole average showed lower than the one by each district. This is analyzed that because, for each points, predicting value is sometimes higher and sometimes lower than experimental value, error rate gets lower. During the analysis period for error rate, looking at the error rate by precedent time for all prediction, the error of the power generation amount of whole wind power generators targeted for measurement and prediction showed 12.5\% 17.5\%, which meant that the greater precedent time gets, the greater error rate gets. For the error rate by daily hour, the error rate from afternoon to night time generally seemed to be high. Fig. 13-Fig. 17 illustrate the error rate of prediction results according to precedent hour.

TABLE VI: ANALYSIS RESULT OF THE ERROR RATE (\%) FOR THE PREDICTION BY WIND POWER PLANT

\begin{tabular}{|c|c|c|c|c|c|}
\hline \multirow{2}{*}{ Division } & \multicolumn{5}{|c|}{ Precedent prediction hour } \\
\cline { 2 - 6 } & $\mathbf{1}$ hours & $\mathbf{6}$ hours & $\mathbf{1 2}$ hours & $\mathbf{2 4}$ hours & $\mathbf{4 8}$ hours \\
\hline $\begin{array}{c}\text { Whole } \\
\text { average }\end{array}$ & 12.5 & 13.3 & 14.0 & 15.7 & 17.5 \\
\hline $\begin{array}{c}\text { Gangwon } \\
\text { Wind Power }\end{array}$ & 14.8 & 15.6 & 16.4 & 18.2 & 19.8 \\
\hline $\begin{array}{c}\text { Mt. Taegi } \\
\text { Wind Power }\end{array}$ & 16.3 & 16.9 & 17.47 & 19.5 & 21.5 \\
\hline $\begin{array}{c}\text { Jeonbuk } \\
\text { Wind Power }\end{array}$ & 10.0 & 10.1 & 10.6 & 11.5 & 11.8 \\
\hline
\end{tabular}

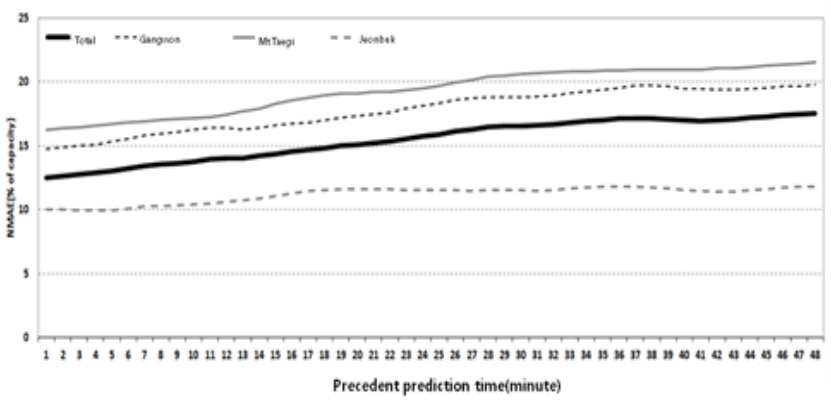

Fig. 13. The error rate by precedent prediction hour of whole wind power generation amount (precedent 1 hour 48 hours).

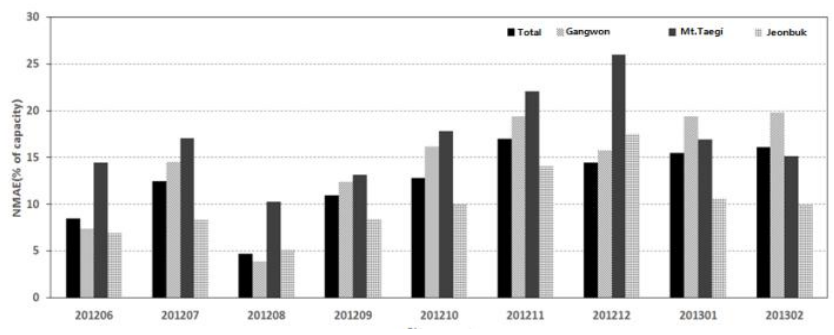

Fig. 14. The error rate by precedent prediction month of whole wind power generation amount (precedent 6 hours).

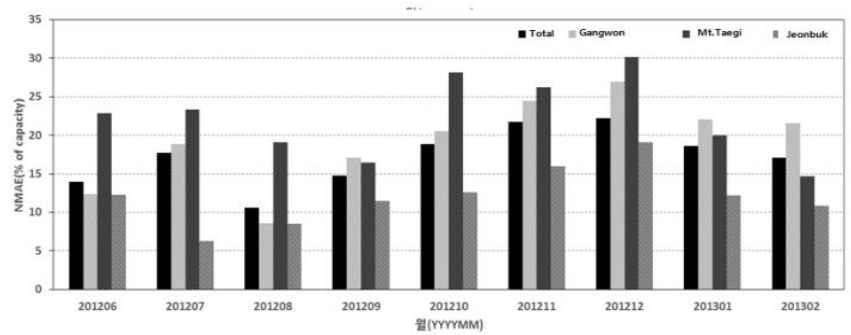

Fig. 15. The error rate by precedent prediction month of whole wind power generation amount (precedent 48 hours).

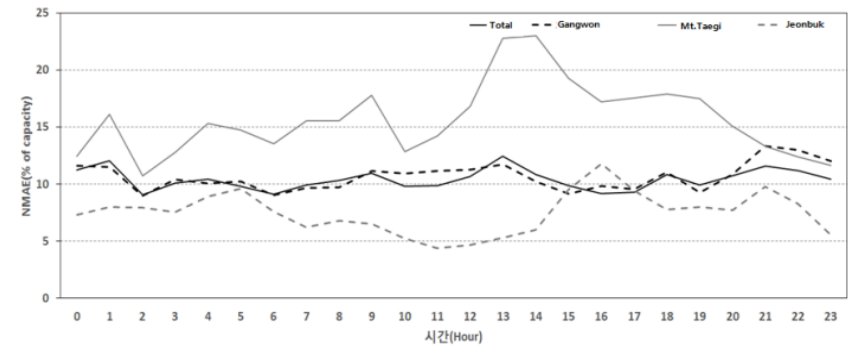

Fig. 16. The error rate by daily precedent prediction hour of whole wind power generation amount (precedent 6 hours) 


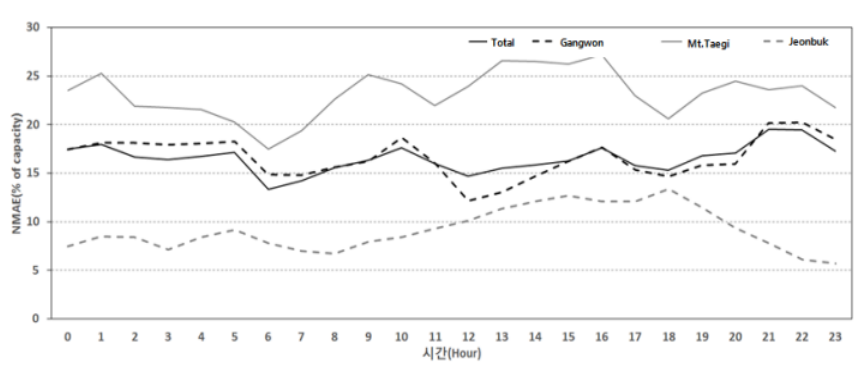

Fig. 17. The error rate by daily precedent prediction hour of whole wind power generation amount (precedent 48 hours).

The study related to the prediction of wind power generation amount was actively progressed with EU and US area as the center where wind energy resource was relatively sufficient [11], [12]. Although various precedent studies were preceded, approaching methods were not so different to solve the problems. The analysis show that it was common that they tried to precede predictions properly combining the physical model and the statistical model to enhance the accuracy in the short-term prediction stage and it was different that the specific model established in the physical model and the statistical model were different little by little considering the characteristics of each region. This study shows the best error rate by accomplishing $15.7 \%$ within 24 hours and $17.5 \%$ within 48 hours.

\section{REFERENCES}

[1] J. Usaola and J. Angarita, "Benefits of short term wind power prediction programs for the integration of wind energy in electricity markets," in Proc. the European Wind Energy Conference, 2006, pp. 2-2.

[2] M. A. Mohandes, T. O. Halawani, S. Rehman, and A. A. Hussain, "Support vector machines for wind speed prediction," Renewable Energy, vol. 29, no. 6, pp. 939-947, 2004.

[3] G. Kariniotakis, J. Halliday, R. Brownsword, I. Marti, A. M. Palomares, I. Cruz, and D. Garrett, "Next generation short-term forecasting of wind power-overview of the ANEMOS project," in Proc. European Wind Energy Conference, 2006, p. 10.

[4] S. Jae-Ju et al., "Comparative analysis on forecasting inaccuracy on electric power forecasting system of distributed power generation," in Proc. International Conference on Computing and Convergence Technology, 2013.

[5] K. Kim, Y. J. Seo, K. S. Moon, and Y. M. Lee, "Real-time wind power prediction system based on smart-grid in Jeju, Korea," Journal of International Council on Electrical Engineering, vol. 2, no. 2, pp. 194-200, 2012.

[6] M. C. Alexiadis, P. S. Dokopoulos, H. S. Sahsamanoglou, and I. M. Manousaridis, "Short-term forecasting of wind speed and related electrical power," Solar Energy, vol. 63, no. 1, pp.61-68, 1998.

[7] A. More and M. C. Deo, "Forecasting wind with neural networks," Marine Structures, vol. 16, no. 1, pp. 35-49, 2003.

[8] R. J. Barthelmie et al., "Quantifying the impact of wind turbine wakes on power output at offshore wind farms," Journal of Atmospheric and Oceanic Technology, vol. 27, no. 8, pp. 1302-1317, 2010.

[9] L. Yi et al., "A new background subtraction method for energy dispersive X-ray fluorescence spectra using a cubic spline interpolation," Nuclear Instruments and Methods in Physics Research
Section A: Accelerators, Spectrometers, Detectors and Associated Equipment, vol. 775, pp. 12-14, 2015.

[10] Picture of typical wind turbine power output with steady wind speed. [Online]. Available: https://qph.is.quoracdn.net/main-qimg-c45f41424b1b4b180b282542 efd16c64?convert_to_webp=true

[11] J. Tambke et al., "Short-term forecasting of offshore wind farm production-developments of the Anemos project," in Proc. 2006 European Wind Energy Conference, EWEC, 2006, p. 13.

[12] F. Vallée, J. Lobry, and O. Deblecker, "Solutions to reduce the impact of wind prediction errors on the classical electrical system operation," Recent Patents on Electrical \& Electronic Engineering (Formerly Recent Patents on Electrical Engineering), vol. 2, no. 1, pp. 13-18, 2009.

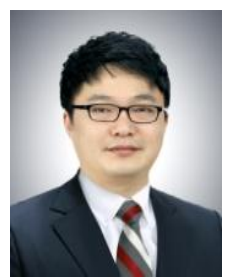

Jun-Sung Kim was born in Chungnam, Korea on April 13, 1981. He received the master degree in computer science from Korea Advanced Institute of Science and Technology (KAIST), Daejeon, Korea, 2008. He is working as a researcher in Software Center, Korea Electric Power Research Institute (KEPRI) since August 2012. He is also in charge of Distributed Energy Resources Interface Standardization in Korea. His research interest is the micro grid software platform. He has published more than 20 papers in peer review journals or international conferences.

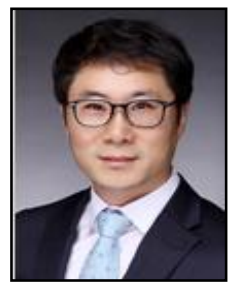

Jin-Ho Shin was born in Chungnam, Korea on July 26, 1970. He received the Ph.D. degree in computer science from Chungbuk National University, Cheongju, Korea, 2010. He is working as a principle researcher in Software Center, Korea Electric Power Research Institute (KEPRI) since February 2011. He is also in charge of Meter Data Management System in Korea. His research interest is the software platform for smart city. He has published more than 30 papers in peer review journals or international conferences.

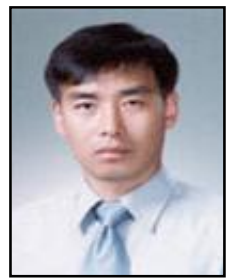

Young-Bae Park was born in Chungnam, Korea on June 28, 1966. He received his master degree in computer science from Chungbuk National University, Cheongju, Korea, 2005. He is working as a senior researcher in Software Center, Korea Electric Power Research Institute (KEPRI) since July 2013. He is also in charge of Micro Grid Common Reference Model Standardization in Korea. His research interest is the software platform for micro grid. He has published more than 10 papers in peer review journals or international conferences.

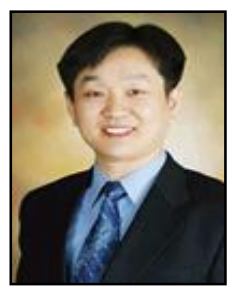

Hee-Jeong Park was born in Chungbuk, Korea on April 23, 1964. He received his master degree in education from Yon-Sei University, Seoul, Korea, 2012. He is working as a principle researcher in Software Center, Korea Electric Power Research Institute (KEPRI) since July 2014. He is also in charge of Software Tech. Development Team in Software Center, KEPRI. His research interest is the software platform for micro grid. He has published more than 5 papers in peer review journals or international conferences. 